Check for updates

Cite this: RSC Adv., 2018, 8, 19818

\title{
Waste wool derived nitrogen-doped hierarchical porous carbon for selective $\mathrm{CO}_{2}$ capture $\uparrow$
}

\author{
Yao Li, (D) ${ }^{\text {ac }}$ Ran Xu, ${ }^{a}$ Xin Wang, ${ }^{b}$ Binbin Wang, (D) *b Jianliang Cao, ${ }^{d}$ Juan Yang ${ }^{\star a c}$ \\ and Jianping Wei ${ }^{\star a c}$
}

The goal of this research is to develop a low-cost porous carbon adsorbent for selective $\mathrm{CO}_{2}$ capture. To obtain advanced adsorbents, it is critical to understand the synergetic effect of textural characteristics and surface functionality of the adsorbents for $\mathrm{CO}_{2}$ capture performance. Herein, we report a sustainable and scalable bio-inspired fabrication of nitrogen-doped hierarchical porous carbon by employing $\mathrm{KOH}$ chemical activation of waste wool. The optimal sample possesses a large surface area and a hierarchical porous structure, and exhibits good $\mathrm{CO}_{2}$ adsorption capacities of $2.78 \mathrm{mmol} \mathrm{g}^{-1}$ and $3.72 \mathrm{mmol} \mathrm{g}^{-1}$ at $25{ }^{\circ} \mathrm{C}$ and $0{ }^{\circ} \mathrm{C}$, respectively, under 1 bar. Additionally, this sample also displays a moderate $\mathrm{CO}_{2} / \mathrm{N}_{2}$ selectivity, an appropriate $\mathrm{CO}_{2}$ isosteric heat of adsorption and a stable cyclic ability. These multiple advantages combined with the low-cost of the raw material demonstrate that this sample is an excellent candidate as an adsorbent for $\mathrm{CO}_{2}$ capture.

Received 28th March 2018 Accepted 16th May 2018

DOI: 10.1039/c8ra02701c

rsc.li/rsc-advances beauty of these systems is that they can work under real flue gas conditions to capture very low concentrations of $\mathrm{CO}_{2}$ in the mixture gas, associated with moisture, and at elevated temperatures. However the long-term cyclic stabilities are still a concerning problem. In comparison to chemical absorption, physical adsorption based on solid adsorbents is regarded as an alternative method. Varieties of solid absorbents including silica, ${ }^{9}$ metal-organic frameworks (MOFs), ${ }^{\mathbf{1 0 - 1 2}}$ organic polymers, ${ }^{13}$ zeolites ${ }^{\mathbf{1 4}}$ and porous carbon materials ${ }^{\mathbf{1 5 , 1 6}}$ have become the focus for $\mathrm{CO}_{2}$ capture research. Among them, porous carbon materials have attracted much attention due to their features of large surface area, high porosity, chemical and thermal stability, hydrophobicity and no toxicity, and they are regarded as the most promising $\mathrm{CO}_{2}$ capture materials. ${ }^{15-19}$

As is well known, carbon adsorbents with remarkable $\mathrm{CO}_{2}$ capacity are commonly those possessing large specific surface areas and hierarchical porous architectures with abundant fine micropores $(<1 \mathrm{~nm})$ and complementary mesopores, in which the fine micropores $(<1 \mathrm{~nm})$ are important for $\mathrm{CO}_{2}$ adsorption, while the mesopores are useful for $\mathrm{CO}_{2}$ diffusion. ${ }^{20-22}$ Meanwhile, due to the fact that $\mathrm{CO}_{2}$ is weakly acidic, nitrogen elements can be introduced into the carbon frameworks. Nitrogen-doped (N-doped) sites can act as basic active sites to enhance the interactions between $\mathrm{CO}_{2}$ molecules and the carbon surface via base-acid interactions, and can subsequently improve the adsorption capacity and selectivity for $\mathrm{CO}_{2} \cdot{ }^{22-24}$ At present, numerous $\mathrm{N}$-doped porous carbon materials have been reported for the capture of $\mathrm{CO}_{2}$, and they are prepared by the carbonation of nitrogen-containing organic polymers. ${ }^{25-28}$ Unfortunately, the high cost of some polymer precursors and the complicated earlier synthetic processes 
make it hard to scale up production of these porous carbon materials and their practical applications. For reducing the cost and making practical applications viable whilst simultaneously considering environmental factors, biomass materials, especially biomass waste, have been widely used as carbon sources because of their low cost, sustainability, and abundance..$^{29-32}$ In addition, biomass precursors naturally contain some useful heteroatoms such as nitrogen that will be anchored on the surface of the carbon framework, and this will enhance the $\mathrm{CO}_{2}$ adsorption capability of the carbon materials. ${ }^{32-34}$ Meanwhile, chemical activation with $\mathrm{KOH}$ is found to be a very common and useful method for the preparation of porous carbon materials, ${ }^{35-37}$ especially biomassderived porous carbon materials. ${ }^{30-34,38}$ For instance, by means of $\mathrm{KOH}$ activation, Guo et al. ${ }^{38}$ successfully transformed waste coffee grounds into an effective porous carbon sorbent material for $\mathrm{CO}_{2}$ capture. Chen et al. ${ }^{30}$ and Yang et $a .^{31}$ used $\mathrm{KOH}$ to activate carbonized coconut shells and develop porous carbon adsorbents for $\mathrm{CO}_{2}$ capture. Liang et al. ${ }^{32}$ reported the synthesis of $\mathrm{N}$-doped microporous carbon by employing the steam-explosion of popcorn and subsequent $\mathrm{KOH}$ activation, in which the resulting carbon material was employed to give a high performance of $\mathrm{CO}_{2}$ capture. $\mathrm{Zhu}$ et $a{ }^{33}$ synthesized $\mathrm{N}$-doped nanoporous carbon from pine cones by means of chemical activation with $\mathrm{KOH}$, and it exhibited a high $\mathrm{CO}_{2}$ capture capacity. Alabadi et al. ${ }^{34}$ obtained highly porous carbon from biomass carbonization and subsequent $\mathrm{KOH}$ activation, and it displayed a high $\mathrm{CO}_{2}$ capture capacity.

Herein, with comprehensive considerations, we report a sustainable and scalable synthesis method by employing waste wool as the raw material. Pre-carbonization and subsequent $\mathrm{KOH}$ activation were used to prepare the $\mathrm{N}$-doped hierarchical porous carbon. We chose waste wool as the carbon precursor mainly due to the following: (I) short wool fibres are generally discarded as waste due to their unsuitability for clothing applications, which wastes a resource; ${ }^{39,40}$ (II) wool is mostly composed of amino acids that are unique renewable natural materials with high nitrogen content; ${ }^{40,41}$ (III) functionalized porous carbon can be fabricated from biomass precursors to meet various demands. The resulting waste wool derived $\mathrm{N}$-doped hierarchical porous carbon prepared by chemical activation with the moderate ratio of $\mathrm{KOH} /$ carbon $=3($ designated as WNPC-3) possessed a large specific surface area of $1351 \mathrm{~m}^{2} \mathrm{~g}^{-1}$, a hierarchical porous structure with a total pore volume of $0.78 \mathrm{~m}^{3} \mathrm{~g}^{-1}$, a micropore volume as high as $0.54 \mathrm{~m}^{3} \mathrm{~g}^{-1}$ and a fine micropore volume up to $0.30 \mathrm{~m}^{3} \mathrm{~g}^{-1}$, and a nitrogen content of $4.41 \mathrm{wt} \%$. The $\mathrm{CO}_{2}$ adsorption capacity of WNPC-3 reached $2.78 \mathrm{mmol} \mathrm{g}^{-1}$ at $25^{\circ} \mathrm{C}$ and $3.73 \mathrm{mmol} \mathrm{g}^{-1}$ at $0{ }^{\circ} \mathrm{C}$, under atmospheric pressure (1 bar). Furthermore, WNPC-3 exhibited a moderate $\mathrm{CO}_{2} / \mathrm{N}_{2}$ selectivity for $\mathrm{CO}_{2}$ capture from flue gas, an appropriate $\mathrm{CO}_{2}$ isosteric heat of adsorption in the range of physical adsorption, and a stable $\mathrm{CO}_{2}$ adsorption capacity after several cycles. Our study may provide a new method for the large-scale production of promising porous carbon adsorbents for selective $\mathrm{CO}_{2}$ capture.

\section{Experimental}

\subsection{Materials}

Waste wool was obtained from Henan, China. Potassium hydroxide $(\mathrm{KOH})$ and hydrochloric acid $(\mathrm{HCl})$ were purchased from Sinopharm Chemical Reagent Co. Ltd. China and used as received without any further purification.

\subsection{Sample preparation}

The waste wool was thoroughly washed with distilled water and dried at $60{ }^{\circ} \mathrm{C}$. The cleaned wool was pre-carbonized at $300{ }^{\circ} \mathrm{C}$ for $2 \mathrm{~h}$ with a heating rate of $3{ }^{\circ} \mathrm{C} \mathrm{min}^{-1}$ under a $\mathrm{N}_{2}$ atmosphere, and was then cooled down to room temperature naturally. To simplify, the pre-carbonized wool was denoted WNC. Hereafter, in a typical $\mathrm{KOH}$-activated process, the WNC $(0.2 \mathrm{~g})$ was mixed with the $\mathrm{KOH}$ activation agent $(0.6 \mathrm{~g})$ in $2.5 \mathrm{ml}$ distilled water with a $\mathrm{KOH} / \mathrm{WNC}$ mass ratio of $3: 1$, and then the resulting mixture was treated with ultrasound for $10 \mathrm{~min}$ to obtain a uniform carbon suspension in the $\mathrm{KOH}$ solution. Subsequently, the mixture was activated under $\mathrm{N}_{2}$ protection at $600^{\circ} \mathrm{C}$ for $1 \mathrm{~h}$ in a tubular furnace with a heating rate of $3{ }^{\circ} \mathrm{C} \mathrm{min}^{-1}$. After complete activation, the as-prepared sample was washed with suitable amounts of $0.1 \mathrm{M} \mathrm{HCl}$ solution and distilled water until neutral, and then dried at $60^{\circ} \mathrm{C}$ for $12 \mathrm{~h}$ to obtain the final product. To investigate the effect of $\mathrm{KOH}$ dosage on the final product, a sequence of contrast experiments were carried out under the same conditions. For the convenience of the following discussion, the wool derived $\mathrm{N}$-doped porous carbon materials prepared under different $\mathrm{KOH}$ dosages were designated as WNPC- $x$ where $x$ represents the weight ratio of KOH/ WNC. For comparison, the WNC directly carbonized at $600{ }^{\circ} \mathrm{C}$ for $1 \mathrm{~h}$ without the addition of $\mathrm{KOH}$ was designated as WNPC.

\subsection{Characterization}

Field emission scanning electron microscopy (FE-SEM, Hitachi S-4800) with an energy dispersive X-ray spectrometer (EDS) and transmission electron microscopy (TEM, JEOL-21) were employed to examine the morphology, microstructure and elemental mapping of the carbon samples. Powder X-ray diffraction (XRD) was performed on a Bruker D8 advanced Xray diffractometer using $\mathrm{Cu} \mathrm{K} \alpha$ radiation $(\lambda=0.15406 \mathrm{~nm})$. Raman spectra were collected at an excitation wavelength of $514 \mathrm{~nm}$ using a Renishaw inVia spectrometer. Fourier transform infrared (FT-IR) spectra were obtained using a Nicolet iS10 FTIR spectrometer. X-ray photoelectron spectroscopy (XPS) was performed on a Thermo Scientific ESCALAB250 equipped with an $\mathrm{Al} \mathrm{K} \alpha$ excitation source. Elemental analysis (C, $\mathrm{H}$ and $\mathrm{N}$ ) was performed on a dry basis using a VarioEL III Elemental Analyzer. Nitrogen adsorption-desorption isotherms were measured on a Quantachrome NOVA1000e sorption analyzer by nitrogen physisorption at $-196{ }^{\circ} \mathrm{C}$ using the conventional volumetric technique. The specific surface area $\left(S_{\mathrm{BET}}\right)$ was calculated according to the multipoint Brunauer-EmmettTeller (BET) method based on adsorption data in the relative pressure range between 0.005 to 0.05 , and the total pore volume was determined from the amount of nitrogen adsorbed at 
a relative pressure of about 0.99 . The pore size distribution (PSD) was determined by non-local density functional theory (NLDFT) using nitrogen adsorption data and assuming a slitshaped pore model. The volume of micropores (pores below 2 $\mathrm{nm}$ ) and the volume of fine micropores (pores below $1 \mathrm{~nm}$ ) were calculated based on PSD curves obtained using the NLDFT method.

\section{$2.4 \mathrm{CO}_{2}$ adsorption measurements}

The $\mathrm{CO}_{2}$ adsorption isotherms of the carbon samples were determined from 0 to 1 bar using an intelligent gravimetric analyzer (IGA-003) at $0{ }^{\circ} \mathrm{C}$ and $25{ }^{\circ} \mathrm{C}$. The sample tube was immersed in an ice-water bath for the $0{ }^{\circ} \mathrm{C}$ test and a thermostatic water bath for the $25{ }^{\circ} \mathrm{C}$ test. Prior to the $\mathrm{CO}_{2}$ adsorption test, the sample was dried and degassed in a vacuum at $200{ }^{\circ} \mathrm{C}$ for $3 \mathrm{~h}$ to remove any guest-molecules. After the sample was cooled down to the adsorption temperature, the dry mass was set and $\mathrm{CO}_{2}$ gas was introduced into the system.

\section{Results and discussion}

\subsection{Physicochemical characterization}

In our synthetic process, two procedures including precarbonization and the subsequent $\mathrm{KOH}$ activation were carried out for the efficient fabrication of wool derived N-doped porous carbon with a hierarchical structure and high surface area; hence, the resulting carbon can be effectively used for selective $\mathrm{CO}_{2}$ capture, as schematically presented in Fig. 1. The morphology and porous structure of representative sample WNPC-3 were studied using scanning electron microscopy (SEM). As shown in Fig. 2a, the SEM image reveals that the carbon sample possesses a sponge-like morphology characterized by many nested net cavities. The surface of WNPC-3 exhibits an extremely 3D porous structure formed by $\mathrm{KOH}$ activation (Fig. 2b). The micropores and mesopores with different pore-sizes of WNPC-3 are interconnected, and can be widely used for $\mathrm{CO}_{2}$ capture (Fig. 2c). The overall morphology and porous structure of sample WNPC-3 were further studied using transmission electron microscopy (TEM). As can be seen

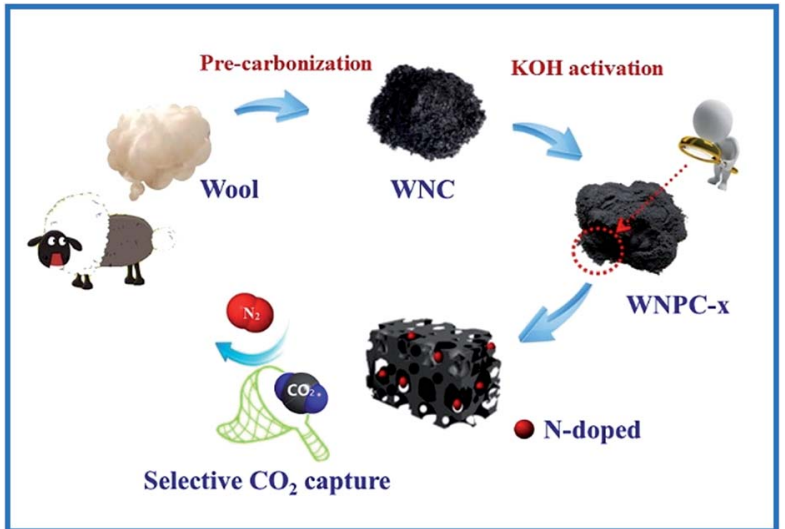

Fig. 1 Schematic illustrating the fabrication of WNPC- $x$ and uses in selective $\mathrm{CO}_{2}$ capture.
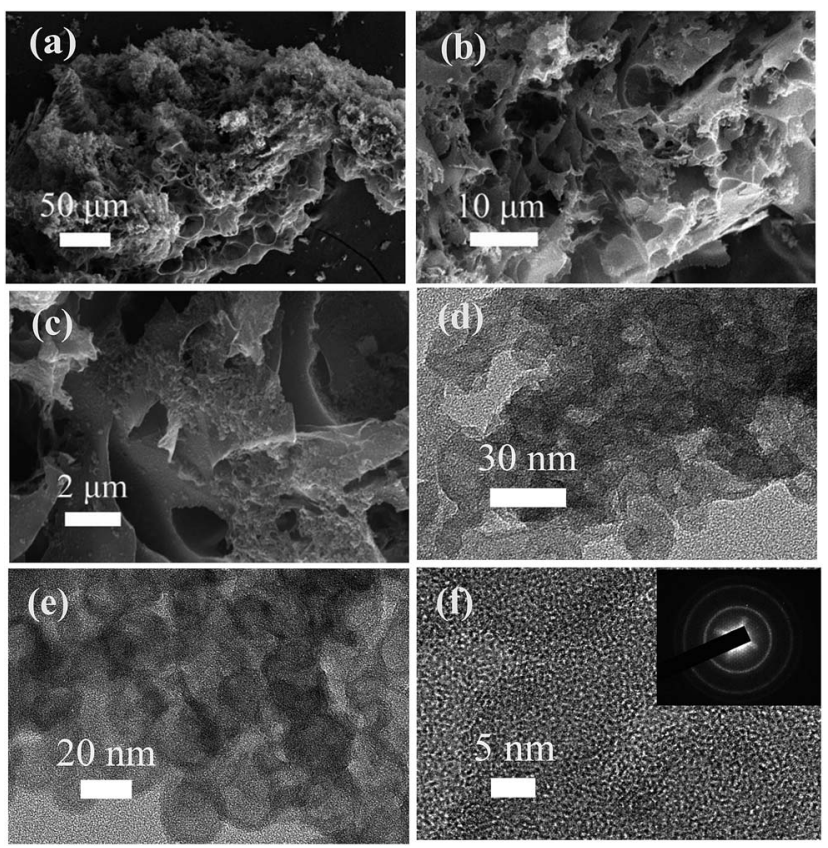

Fig. 2 (a-c) FE-SEM images, (d and e) TEM images and (f) HR-TEM image of the sample WNPC-3. The inset shows the SAED pattern.

in Fig. $2 \mathrm{~d}$ and e, the low magnification view confirms that WNPC-3 maintains a continuous sponge-like morphology with a cross-linked porous texture, which is in agreement with previous SEM results. The high-resolution transmission electron microscopy (HR-TEM) image (Fig. 2f) shows that the randomly distributed worm-like micropores are formed by the stacking of disordered graphene layers. ${ }^{16}$ The selected area electron diffraction (SAED) pattern of WNPC-3 (inset in Fig. 2f) exhibits typical diffuse rings, reflecting the amorphous nature of carbon.

To determine the crystallite structure of a sample of WNPC3 , XRD and Raman spectra were recorded. The two broad peaks at around $22.5^{\circ}$ and $43^{\circ}$ in the XRD spectrum (Fig. 3a) correspond to typical reflections of the (002) and (100) planes of graphite, indicating the amorphous structure of WNPC-3. ${ }^{42,43}$ The Raman spectrum (Fig. 3b) exhibits two characteristic peaks for WNPC-3 at around $1330 \mathrm{~cm}^{-1}$ (D-band) and $1590 \mathrm{~cm}^{-1}$ (Gband), which correspond to disordered carbon and the ordered graphite lattice, respectively..$^{\mathbf{4 2 - 4 4}}$ The intensity ratio of the two bands $\left(I_{\mathrm{D}} / I_{\mathrm{G}}\right)$ is known to be proportional to the number of defect sites in the graphitic carbon, that is, the higher the $I_{\mathrm{D}} /$ $I_{\mathrm{G}}$ ratio is, the lower the graphitization is. ${ }^{\mathbf{4 3 , 4 4}}$ The calculated $I_{\mathrm{D}} /$ $I_{\mathrm{G}}$ ratio of WNPC-3 is 1.12 , confirming that many defects exist in the carbon structure, which is consistent with the XRD results. The chemical bonding information of WNPC-3 was investigated using Fourier transform infrared (FT-IR) spectroscopy (Fig. 3c). The appearance of a broad absorption band at around $3430 \mathrm{~cm}^{-1}$ can be assigned to $\mathrm{N}-\mathrm{H}$ and/or $\mathrm{O}-\mathrm{H}$ stretching vibrations. ${ }^{34}$ The existence of a band at $1620 \mathrm{~cm}^{-1}$ indicates the presence of $\mathrm{C}=\mathrm{C}$ stretching vibrations in aromatic rings for the activated carbon. ${ }^{27}$ The peak at around $1200-1000 \mathrm{~cm}^{-1}$ relates to the stretching vibrations of $\mathrm{C}-\mathrm{N}$ and/or $\mathrm{C}-\mathrm{O} .{ }^{25}$ The weak peak 

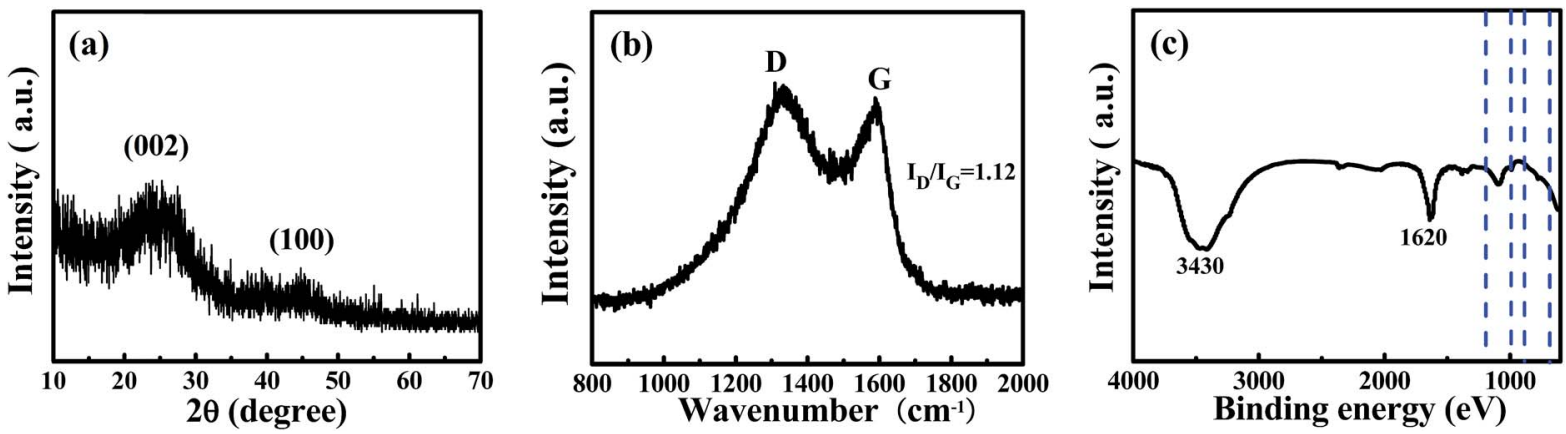

Fig. 3 (a) XRD, (b) Raman and (c) FT-IR spectra of the sample of WNPC-3.

between 900 and $650 \mathrm{~cm}^{-1}$ can be assigned to $\mathrm{N}-\mathrm{H}$ and/or C-H out-of-plane deformation vibrations. ${ }^{25,26}$ Therefore, the FT-IR spectra preliminarily confirm that $\mathrm{N}-\mathrm{H}$ and $\mathrm{C}-\mathrm{N}$ species are in WNPC-3.

To further analyze the surface chemical states and the composition of WNPC-3, X-ray photoelectron spectroscopy (XPS) was employed to systematically investigate the intrinsic nature of the $\mathrm{C}, \mathrm{N}$ and $\mathrm{O}$ species in WNPC-3. The full survey spectrum clearly shows the existence of three typical peaks for $\mathrm{C}$ $1 \mathrm{~s}, \mathrm{~N} 1 \mathrm{~s}$ and $\mathrm{O} 1 \mathrm{~s}$ in the sample of WNPC-3 (Fig. 4a). The representative spectrum of $\mathrm{C} 1 \mathrm{~s}$ can be deconvoluted into five peaks (Fig. 4b). The peak at about $285.9 \mathrm{eV}$ confirms the presence of C-N in WNPC-3, while the dominant peak at $284.7 \mathrm{eV}$ could be attributed to C-C. ${ }^{26,45}$ The peaks at about $285.4 \mathrm{eV}$, $286.7 \mathrm{eV}$ and $287.8 \mathrm{eV}$ correspond to $\mathrm{C}-\mathrm{OH},{ }^{26} \mathrm{C}-\mathrm{O}^{34}$ and $\mathrm{C}=\mathrm{O},{ }^{41}$ respectively. The high resolution $\mathrm{N} 1 \mathrm{~s}$ spectrum reveals the chemical states of nitrogen atoms in WNPC-3 (Fig. 4c). The deconvoluted spectrum displays three nitrogen species with binding energies of $400.1 \mathrm{eV}, 398.5 \mathrm{eV}$ and $402.8 \mathrm{eV}$, which can be attributed as pyrrolic-N/pyridonic-N, pyridinic-N and pyridine N-oxides, respectively. ${ }^{25,26,41,45}$ Pyrrolic-N and pyridonic- $\mathrm{N}$ are hard to distinguish from each other within the accuracy of
XPS measurements, however, considering the greater stability of pyridonic- $\mathrm{N}$ compared to pyrrolic-N, pyridonic- $\mathrm{N}$ is more likely to be present in WNPC-3. ${ }^{25-27}$ The corresponding peak areas analysis shows that the amount of pyridonic- $\mathrm{N}$ is higher that of the two others, and it has been reported that pyridonic-N acts as a main anchor for $\mathrm{CO}_{2}$ capture. ${ }^{16,25,26}$ Three characteristic peaks are observed at $531.3 \mathrm{eV}, 533.1 \mathrm{eV}$ and $534.9 \mathrm{eV}$ in the deconvoluted $\mathrm{O} 1 \mathrm{~s}$ spectrum (Fig. $4 \mathrm{~d}$ ), which can be ascribed to $\mathrm{O}=\mathrm{C}, \mathrm{O}-\mathrm{C}$, and chemisorbed $\mathrm{O}_{2}$ and/or $\mathrm{H}_{2} \mathrm{O}$ bound to WNPC-3 respectively. ${ }^{26,41,45}$

As previously reported, ${ }^{46,47}$ the $\mathrm{C}-\mathrm{O}$ and $\mathrm{C}=\mathrm{O}$ functional groups may play a important role in $\mathrm{CO}_{2}$ adsorption and $\mathrm{CO}_{2} / \mathrm{N}_{2}$ selectivity, due to enhanced interaction forces between the $\mathrm{O}$ decorated carbon framework and $\mathrm{CO}_{2}$ molecules. Additionally, the SEM energy dispersive X-ray spectroscopy (EDS) mapping analysis for WNPC-3 shows that the elements of $\mathrm{C}, \mathrm{N}$ and $\mathrm{O}$ are uniformly distributed in the sample (Fig. $4 \mathrm{e}-\mathrm{h}$ ).

The chemical compositions of a sample of WNPC-3 as well as the other samples of WNPC, WNPC- 1 and WNPC- 5 were further investigated by $\mathrm{C}, \mathrm{N}$ and $\mathrm{O}$ elemental analysis, as presented in Table 1. As can be seen, the nitrogen content decreases from $11.25 \mathrm{wt} \%$ (un-activated WNPC) to $3.70 \mathrm{wt} \%$ (strongly activated
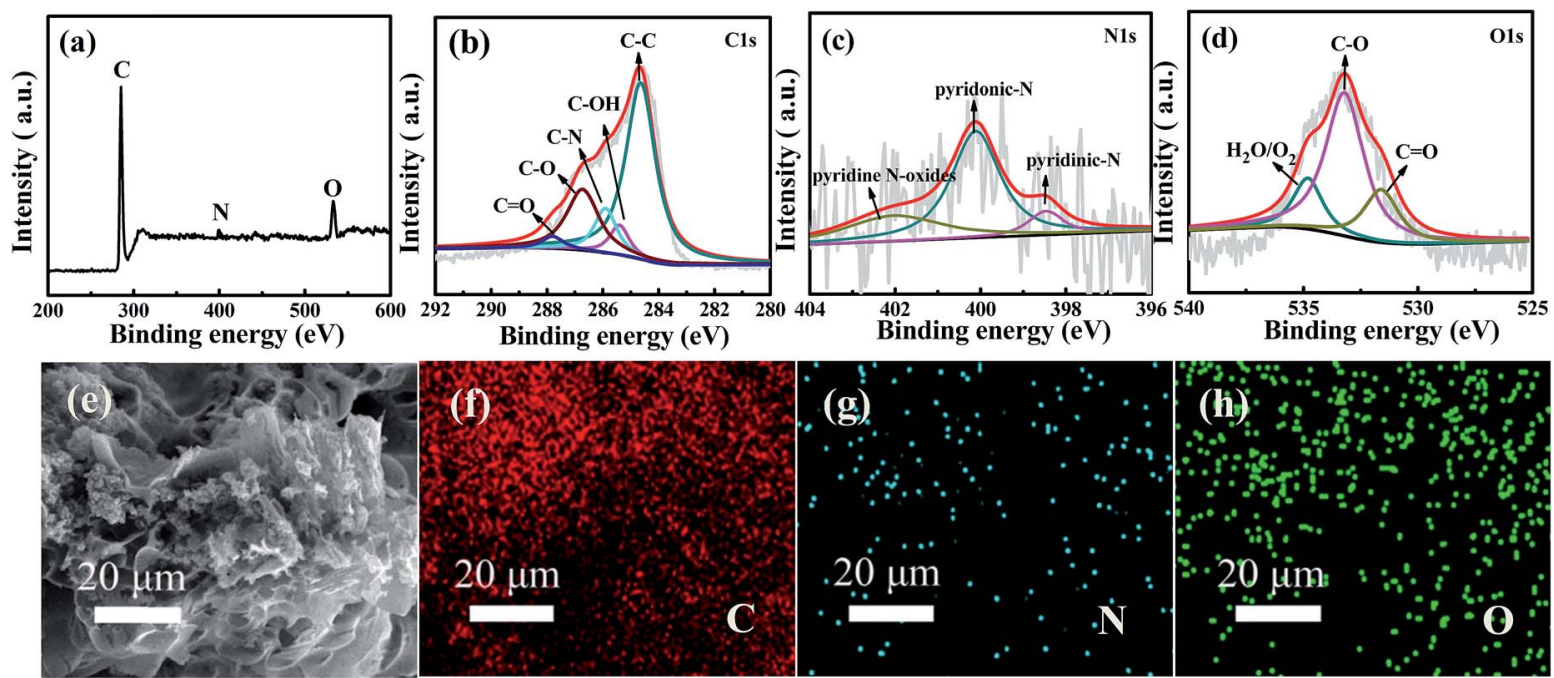

Fig. 4 XPS spectra of WNPC-3: (a) high-resolution full survey spectrum of (b) C 1s, (c) N 1s and (d) O 1s; (e-h) SEM image and the corresponding EDS element mappings of (f) $\mathrm{C},(\mathrm{g}) \mathrm{N}$ and (h) O for WNPC-3. 
Table 1 Chemical compositions of wool-derived carbon materials

\begin{tabular}{lrlll}
\hline & \multicolumn{4}{l}{ Elemental composition $(\mathrm{wt} \%)$} \\
\cline { 2 - 5 } Sample & $\mathrm{N}^{a}$ & $\mathrm{C}^{a}$ & $\mathrm{H}^{a}$ & $\mathrm{O}^{b}$ \\
\hline WNCP & 11.25 & 71.90 & 1.37 & 15.48 \\
WNCP-1 & 4.57 & 70.73 & 1.64 & 23.06 \\
WNCP-3 & 4.14 & 69.65 & 1.42 & 24.79 \\
WNCP-5 & 3.70 & 67.47 & 1.68 & 27.15
\end{tabular}

${ }^{a}$ Obtained from $\mathrm{C}, \mathrm{H}$ and $\mathrm{N}$ elemental analysis. ${ }^{b}$ Calculated by difference.

WNPC-5). Approximately $4.57 \mathrm{wt} \%$ of nitrogen is detected for the low-activated WNPC-1, while about $4.14 \mathrm{wt} \%$ is detected for moderately activated WNPC-3. The nitrogen content decreases with the increasing $\mathrm{KOH} / \mathrm{WNC}$ weight ratio, which is consistent with the previously reported literature..$^{23-27}$ There is a rapid drop in nitrogen content from un-activated WNPC to the activated WNPC-1. The nitrogen content decreases slowly when the $\mathrm{KOH} /$ WNC ratio increases from 1 to 5 , especially with a $\mathrm{KOH} / \mathrm{WNC}$ ratio from 1 to 3 . However, with the nitrogen content decrease, the carbon content also decreases concomitantly with the $\mathrm{KOH}$ activation, while the hydrogen content appears to be relatively unchanged. Furthermore, the oxygen content is increased with the increase in the $\mathrm{KOH} / \mathrm{WNC}$ ratio in the samples, from WNCP to WNCP-1 to WNCP-3 to WNCP-5, because the $\mathrm{KOH}$ activation promotes the oxidation process of the carbon. ${ }^{48}$ The $\mathrm{KOH}$ activated carbon materials contain more $\mathrm{O}$ atoms, which could be attributed to the reaction of carbon with $\mathrm{CO}_{2}$ evolved from $\mathrm{K}_{2} \mathrm{CO}_{3}$ and $\mathrm{K}_{2} \mathrm{O}$, as well as oxygen chemisorption from air. ${ }^{\mathbf{4 9 , 5 0}}$ The increased oxygen content from WNCP to WNCP-5 should be due to the increased $\mathrm{KOH} / \mathrm{WNC}$ ratio, which is consistent with the behavior of $\mathrm{KOH}$ activated carbon materials we have reported previously. ${ }^{26,45}$ Therefore the activated carbon materials can preserve more oxygen functional groups such as $\mathrm{C}=\mathrm{O}$ and $\mathrm{C}-\mathrm{O} .^{46,51}$

The porosities of WNPC and the WNPC- $x$ series were investigated by nitrogen adsorption-desorption isothermal analysis, as presented in Fig. 5, and the textural characteristics are shown in Table 2. The salt concentration (such as the $\mathrm{KOH}$ amount used in activation) can alter the shape of the adsorption-
Table 2 Textural characteristics and $\mathrm{CO}_{2}$ uptakes for wool-derived carbon materials

\begin{tabular}{|c|c|c|c|c|c|}
\hline \multirow[b]{2}{*}{ Sample } & \multicolumn{4}{|c|}{ Textural characteristics } & \multirow{2}{*}{$\begin{array}{l}\mathrm{CO}_{2} \text { uptake } \\
25^{\circ} \mathrm{C} \\
\left(\mathrm{mmol} \mathrm{g}^{-1}\right)\end{array}$} \\
\hline & $S_{\mathrm{BET}}{ }^{a}$ & $V_{\text {total }}^{b}$ & $V_{\text {micro }}{ }^{c}$ & $\mathrm{PV}_{1 \mathrm{~nm}}{ }^{d}$ & \\
\hline WNCP & 447 & 0.22 & 0.18 & 0.11 & 1.48 \\
\hline WNCP-1 & 1010 & 0.57 & 0.37 & 0.15 & 2.33 \\
\hline WNCP-3 & 1352 & 0.78 & 0.54 & 0.30 & 2.78 \\
\hline WNCP-5 & 1420 & 0.86 & 0.52 & 0.18 & 2.35 \\
\hline
\end{tabular}

${ }^{a} S_{\mathrm{BET}}$ is the specific surface area calculated by BET equations based on the adsorption data in the $P / P_{0}$ range from 0.005 to $0.05 .{ }^{b} V_{\text {total }}$ is the total pore volume obtained at $P / P_{0} \sim 0.99 .{ }^{c} V_{\text {micro }}$ is the cumulative micropore volume (pore size $<2 \mathrm{~nm}$ ) analyzed using the NLDFT method. ${ }^{d} \mathrm{PV}_{1 \mathrm{~nm}}$ is the cumulative fine micropore volume (pore size $<1 \mathrm{~nm}$ ) analyzed using the NLDFT method.

desorption isotherm, and thus alter the specific surface area and especially the pore-size distribution of the activated carbon materials. $^{36-38}$ As can be seen from Fig. 5a, the un-activated sample WNPC has a very low nitrogen adsorption in the low pressure range and does not display a hysteresis loop in the middle pressure range, which reveals that only a small number of micropores exist in the WNPC. In contrast, all of the activated WNPC- $x$ series samples display significantly enhanced nitrogen adsorption, exhibiting typical type-I/IV isothermal curves with sharp increases at low pressure and obvious hysteresis loops at middle pressures, which implies that micropores and mesopores all exist in WNPC- $x$. As the ratio of $\mathrm{KOH} / \mathrm{WNC}$ increased from 1 to 3 and 5 , the adsorption curve increased steeply at low pressure, indicating the development of the specific surface area and microporosity. ${ }^{36,38}$ Moreover, with the increasing $\mathrm{KOH} /$ WNC ratio, the isotherm knees of the activated samples are gradually widened to some extent, indicating the generation of some large micropores and/or small mesopores in the carbon framework. ${ }^{52,53}$ Fig. 5b shows the corresponding pore size distribution (PSD) curves of all samples, and these were calculated using the NLDFT model. The pore size of WNPC mainly centers at $0.93 \mathrm{~nm}$ indicating a microporous structure. The PSD curves of the activated WNPC- $x$ series are distributed in the range of $0.50-4.00 \mathrm{~nm}$ indicating hierarchical porous structures. Interestingly, all activated samples (WNPC-1, WNPC-3
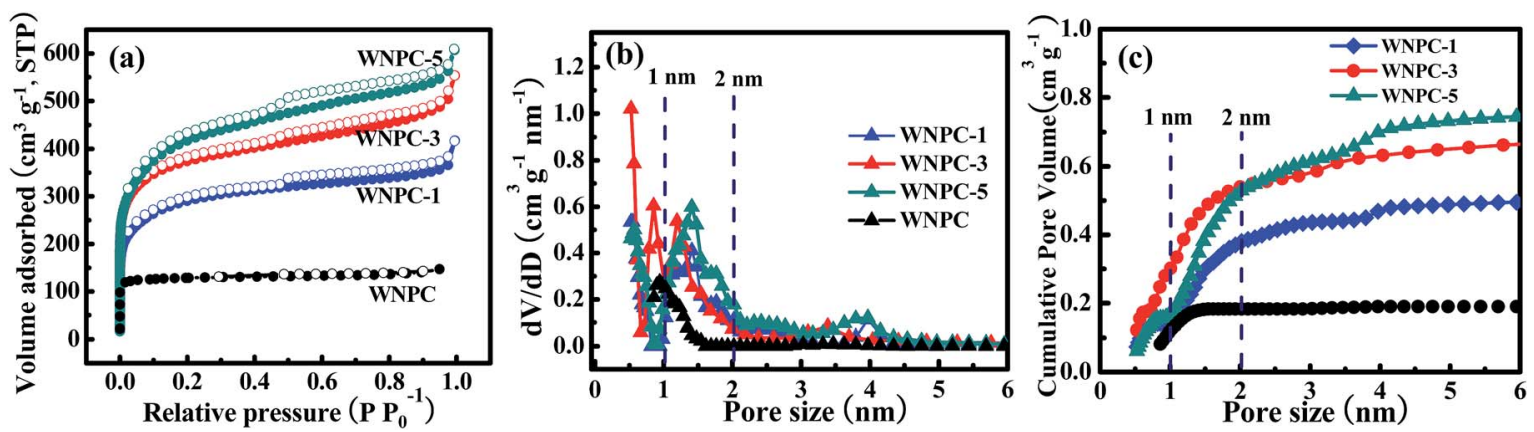

Fig. 5 (a) Nitrogen adsorption-desorption isotherms, (b) PSDs and (c) cumulative pore volumes against pore sizes for wool-derived carbon materials. 
and WNPC-5) possess an important fraction of fine micropores $(<1 \mathrm{~nm})$. In particular, the moderately activated WNPC-3 exhibits an extraordinarily strong peak at $0.52 \mathrm{~nm}$, indicating a large number of fine micropores $(<1 \mathrm{~nm})$ in the carbon framework. Furthermore, WNPC-3 also has two moderately strong peaks at $0.84 \mathrm{~nm}$ and $1.19 \mathrm{~nm}$, and one weak peak at around $3.5 \mathrm{~nm}$. In contrast, the low-activated WNPC-1 only exhibits two moderately strong peaks at $0.50 \mathrm{~nm}$ and $1.39 \mathrm{~nm}$, and one weak peak at about $2.5 \mathrm{~nm}$. Similarly, the strongly activated WNPC-5 only has two moderately strong peaks at $0.57 \mathrm{~nm}$ and $1.41 \mathrm{~nm}$, and two weak peaks at around $2.5 \mathrm{~nm}$ and $4 \mathrm{~nm}$. However, these PSD curves are slightly enlarged with the increasing $\mathrm{KOH} / \mathrm{WNC}$ ratio, and this is probably caused by merging of neighboring small micropores into mesopores or larger ones due to the continuous $\mathrm{KOH}$ activation. ${ }^{38,52-54}$ The pore structures can be developed by the evolution of gaseous byproducts during $\mathrm{KOH}$ activation. ${ }^{36,38}$ To the best of our knowledge, the chemical reaction between $\mathrm{KOH}$ and carbon proceeds as follows: $6 \mathrm{KOH}+\mathrm{C} \rightarrow 2 \mathrm{~K}+3 \mathrm{H}_{2}+2 \mathrm{~K}_{2} \mathrm{CO}_{3}$, followed by $\mathrm{K}_{2} \mathrm{CO}_{3}$ decomposition and the reaction of $\mathrm{K} / \mathrm{K}_{2} \mathrm{CO}_{3} / \mathrm{CO}_{2}$ with carbon ${ }^{36,55}$ Thus with increasing $\mathrm{KOH}$ activation, pore widening is observed. The progressive $\mathrm{KOH}$ etching on the carbon results in a gradual increase in both the specific surface area and the total pore volume. From Table 2, it can be observed that the strongly activated WNPC-5 has the largest specific area $\left(S_{\mathrm{BET}}\right)$ and total pore volume $\left(V_{\text {total }}\right)$ of $1420 \mathrm{~m}^{2} \mathrm{~g}^{-1}$ and $0.86 \mathrm{~m}^{3} \mathrm{~g}^{-1}$, respectively, which are larger than those of un-activated WNPC $\left(S_{\mathrm{BET}}=447 \mathrm{~m}^{2} \mathrm{~g}^{-1}\right.$ and $\left.V_{\text {total }}=0.20 \mathrm{~m}^{3} \mathrm{~g}^{-1}\right)$, low-activated WNPC-1 $\left(S_{\text {BET }}=1010 \mathrm{~m}^{2} \mathrm{~g}^{-1}\right.$ and $\left.V_{\text {total }}=0.57 \mathrm{~m}^{3} \mathrm{~g}^{-1}\right)$ and moderately activated WNPC-3 $\left(S_{\mathrm{BET}}=1352 \mathrm{~m}^{2} \mathrm{~g}^{-1}\right.$ and $V_{\text {total }}=$ $0.78 \mathrm{~m}^{3} \mathrm{~g}^{-1}$ ). However, to the best of our knowledge, besides the specific surface area and total pore volume, the micropore volume $\left(V_{\text {micro }}\right)$ and fine micropore volume $\left(\mathrm{PV}_{1 \mathrm{~nm}}\right)$ are all very important for $\mathrm{CO}_{2}$ capture. ${ }^{53,54,56-58}$ By analyzing the cumulative pore volume against the pore size (Fig. 5c), it is worth noting that WNPC-3 possesses the largest $V_{\text {micro }}$ and $\mathrm{PV}_{1 \mathrm{~nm}}$ of $0.54 \mathrm{~m}^{3}$ $\mathrm{g}^{-1}$ and $0.30 \mathrm{~m}^{3} \mathrm{~g}^{-1}$, respectively, which are much larger than those of WNPC $\left(V_{\text {micro }}=0.18 \mathrm{~m}^{3} \mathrm{~g}^{-1}\right.$ and $\left.\mathrm{PV}_{1 \mathrm{~nm}}=0.11 \mathrm{~m}^{3} \mathrm{~g}^{-1}\right)$, WNPC-1 $\left(V_{\text {micro }}=0.37 \mathrm{~m}^{3} \mathrm{~g}^{-1}\right.$ and $\left.\mathrm{PV}_{1 \mathrm{~nm}}=0.15 \mathrm{~m}^{3} \mathrm{~g}^{-1}\right)$ and WNPC-5 $\left(V_{\text {micro }}=0.52 \mathrm{~m}^{3} \mathrm{~g}^{-1}\right.$ and $\left.\mathrm{PV}_{1 \mathrm{~nm}}=0.18 \mathrm{~m}^{3} \mathrm{~g}^{-1}\right)$, as can be seen in Table 2. Furthermore, the percentage of microporosity $\left(V_{\text {micro }} / V_{\text {total }}\right)$ for WNPC-3 can reach $69 \%$, which is higher than other activated carbon samples (WNPC-1 is $64 \%$ and WNPC-5 is $60 \%$ ). Although the surface area and total pore volume of WNPC-3 are smaller than those of WNPC-5, the $\mathrm{CO}_{2}$ adsorption capability requires the co-operation of the micropore volume, the fine micropore volume and the percentage of microporosity, which can effectively guarantee the $\mathrm{CO}_{2}$ capture performance for WNPC-3.

\subsection{Adsorption performance}

The $\mathrm{CO}_{2}$ adsorption isotherms for the carbon samples were investigated at $25{ }^{\circ} \mathrm{C}$ under atmospheric pressure ( 1 bar), as shown in Fig. 6a. As Gadipelli et al. ${ }^{35,36,59}$ previously reported, the low pressure ( $\sim 1$ bar) adsorption behavior is mainly dependent on the narrow pore size distribution in the micropore region, due to the caging effect, particularly for those pores smaller than $1 \mathrm{~nm} .{ }^{20,59-61}$ WNPC-3 exhibits a significant fine micropore volume (Table 2), which can be attributed to its large number of fine micropores (centred on $0.52 \mathrm{~nm}$ and $0.84 \mathrm{~nm}$ ). Therefore, WNPC-3 demonstrates a good $\mathrm{CO}_{2}$ adsorption capacity of $2.78 \mathrm{mmol} \mathrm{g}^{-1}$ (at 1 bar and $25^{\circ} \mathrm{C}$ ), which can be compared with those porous carbon materials with similar specific surface areas and/or pore-size distribution structures (Table S1†). Among the WNPC and WNPC- $x$ samples, the corresponding relationship between $\mathrm{CO}_{2}$ uptake and fine micropore volume can be clearly seen (Fig. 6b). WNPC-3 exhibits an obviously better $\mathrm{CO}_{2}$ uptake $\left(2.78 \mathrm{mmol} \mathrm{g}^{-1}\right)$ than those of WNCP (1.48 mmol g ${ }^{-1}$ ), WNPC-1 $\left(2.33 \mathrm{mmol} \mathrm{g}^{-1}\right)$ and WNPC-5 (2.35 mmol g${ }^{-1}$ ) (Table 2). The presence of a large number of fine micropores is interesting for gas storage applications.

Therefore, taking WNPC- 3 as the representative sample, the $\mathrm{CO}_{2}$ adsorption performance was measured at $0{ }^{\circ} \mathrm{C}$ and 1.0 bar, and it exhibited a larger $\mathrm{CO}_{2}$ adsorption capacity of $3.72 \mathrm{mmol}$ $\mathrm{g}^{-1}$ than that at $25{ }^{\circ} \mathrm{C}$ (Fig. 6c), indicating that the $\mathrm{CO}_{2}$ adsorption is an exothermic process. As can be seen, the $\mathrm{CO}_{2}$ uptake increases steadily without a distinct plateau in the isotherm for the entire pressure range, indicating that more $\mathrm{CO}_{2}$ can be adsorbed at higher pressures. Thus, the $\mathrm{CO}_{2}$ capture performance for WNPC-3 was further measured at a high pressure of 10 bar (under $0{ }^{\circ} \mathrm{C}$ ), and it could reach up to $10.39 \mathrm{mmol} \mathrm{g}^{-1}$ (Fig. S1†).

Besides the high uptake of $\mathrm{CO}_{2}$, an excellent $\mathrm{CO}_{2}$ absorbent should also demonstrate high $\mathrm{CO}_{2}$ selectivity against other gases such as $\mathrm{N}_{2}$. As shown in Fig. $6 \mathrm{c}$, the adsorption capacity of $\mathrm{N}_{2}$ by WNPC- 3 was also measured at $25^{\circ} \mathrm{C}$ under 1 bar pressure. Clearly, the uptake of $\mathrm{N}_{2}$ is just $0.36 \mathrm{mmol} \mathrm{g}^{-1}$, which is much lower than the uptake of $\mathrm{CO}_{2}$ under the same conditions. In fact, the $\mathrm{CO}_{2}$ uptake is about 7.7 times the $\mathrm{N}_{2}$ adsorption (Fig. 6c), and such a property is essential for $\mathrm{CO}_{2}$ capture. The $\mathrm{CO}_{2} / \mathrm{N}_{2}$ selectivity was measured using Henry's law constants, which can be calculated from the ratio of the initial slopes for the pure gas isotherms. ${ }^{62-64}$ According to the initial slope calculation, the selectivity for $\mathrm{CO}_{2}$ over $\mathrm{N}_{2}$ for WNPC-3 is about 23 at $25{ }^{\circ} \mathrm{C}$ (Fig. S2 $\dagger$ ), indicating a high selectivity towards $\mathrm{CO}_{2}$. In addition, we further used ideal adsorbed solution theory (IAST) ${ }^{65-68}$ to predict $\mathrm{CO}_{2} / \mathrm{N}_{2}$ selectivity in binary gas mixtures using only pure gas isotherms measured at $25{ }^{\circ} \mathrm{C}$. In the calculations, the ratio of $\mathrm{CO}_{2} / \mathrm{N}_{2}$ is assumed to be $15 / 85$, which is a typical component of flue gas. . $^{6,37,66,67,69}$ Herein, the dual-site Langmuir model (DL) and the single-site Langmuir model (L) were chosen to fit the $\mathrm{CO}_{2}$ and $\mathrm{N}_{2}$ adsorption isotherms, respectively, and then DL/L-IAST was utilized to estimate the $\mathrm{CO}_{2} / \mathrm{N}_{2}$ selectivity of WNPC-3 (Fig. S3 $\dagger$ ). As depicted in Fig. $6 \mathrm{~d}$, the IAST selectivity for $\mathrm{CO}_{2} / \mathrm{N}_{2}$ of WNPC-3 can reach 16 at $25^{\circ} \mathrm{C}$ and 1 bar, indicating that it is an excellent prospect for industrial applications. To the best of our knowledge, $\mathrm{CO}_{2}$ exhibits a higher quadrupole moment and polarizability than $\mathrm{N}_{2}$, and in comparison, $\mathrm{N}_{2}$ is much more chemically inert and exhibits lower polarizability than $\mathrm{CO}_{2} \cdot{ }^{68}$ Therefore, the selectivity is influenced by the presence of $\mathrm{N}$ in the carbon framework, because $\mathrm{N}$ will create some electrostatic microdomains within the pore volume, which can play an important role in 

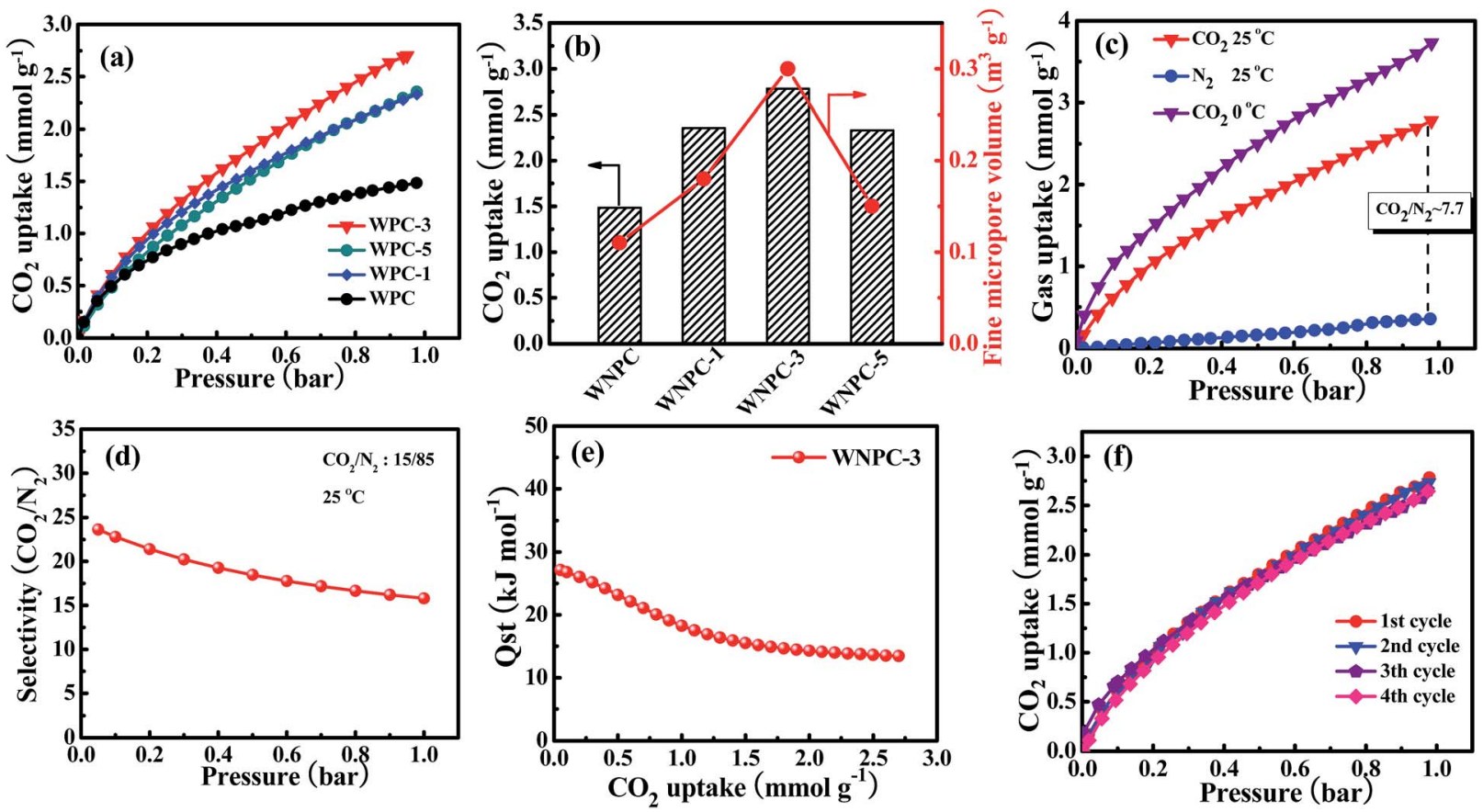

Fig. 6 (a) $\mathrm{CO}_{2}$ adsorption isotherms at $25^{\circ} \mathrm{C}$ and (b) corresponding relationship of $\mathrm{CO}_{2}$ uptake and fine micropore volume for the carbon samples; (c) $\mathrm{CO}_{2}$ and $\mathrm{N}_{2}$ adsorption isotherms at $25^{\circ} \mathrm{C}$ and $0{ }^{\circ} \mathrm{C}$, (d) IAST selectivity for $\mathrm{CO}_{2}$ over $\mathrm{N}_{2}$ collected at $25^{\circ} \mathrm{C}$ (assuming CO$/ \mathrm{N}_{2}$ is 15 / 85), (e) $\mathrm{CO}_{2}$ isosteric heats of adsorption and (f) $\mathrm{CO}_{2}$ multicycle adsorption isotherms at $25^{\circ} \mathrm{C}$ for WNPC-3.

segregating the quadrupolar fluids $\mathrm{N}_{2}$ and $\mathrm{CO}_{2}$ through dipole and quadrupole moments. ${ }^{37}$ Furthermore, the preserved oxygen functional groups in the carbon framework also play a crucial role in $\mathrm{CO}_{2} / \mathrm{N}_{2}$ selectivity, due to the enhanced interaction forces between the O-decorated carbon framework and $\mathrm{CO}_{2}$ molecules. ${ }^{46,47}$ However, comparing with some other carbon materials reported in the literature (Table S1 $\dagger$ ), the $\mathrm{CO}_{2} / \mathrm{N}_{2}$ selectivity of WNPC-3 is just moderate. The moderate $\mathrm{CO}_{2} / \mathrm{N}_{2}$ selectivity can be explained by the large number of micropores (ca. 0.52-1.19 nm), in which $\mathrm{N}_{2}$ may experience higher binding energies from the carbon surface through van der Waals' or electrostatic forces..$^{37}$ In addition, the selectivity of WNPC-3 was obtained from the pure gas adsorption isotherms, which assumes the interactions between the fluid molecules are negligible; therefore, the selectivity value can be regarded as a practical maximum. ${ }^{37}$

As we know, the overall effects of micropore size and $\mathrm{N}-/ \mathrm{O}-$ dopants in the porous carbon materials are to increase the adsorbent-adsorbate interaction energy, which may incur a greater energy penalty for regeneration..$^{38,68}$ Therefore, to understand the interaction strength of $\mathrm{CO}_{2}$ molecules with WNPC-3, the isosteric heat of adsorption $\left(Q_{\mathrm{st}}\right)$ for WNPC-3 was calculated using a variant of the Clausius-Clapeyron equation, ${ }^{38,63,66,70}$ which was accomplished by collecting $\mathrm{CO}_{2}$ adsorption isotherms at $0{ }^{\circ} \mathrm{C}$ and $25{ }^{\circ} \mathrm{C}$ and fitting the data to the DL model (Fig. S3 $\dagger$ ). As displayed in Fig. 6e, the calculated $Q_{\text {st }}$ for WNPC-3 is in the range of $27-13 \mathrm{~kJ} \mathrm{~mol}^{-1}$, with the $\mathrm{CO}_{2}$ uptake varying from 0.05 to $2.7 \mathrm{mmol} \mathrm{g}^{-1}$. At low $\mathrm{CO}_{2}$ loading, the high initial $Q_{\mathrm{st}}$ value leads to a preferential adsorption of $\mathrm{CO}_{2}$ over $\mathrm{N}_{2}$, which can be attributed to the $\mathrm{CO}_{2}$ molecules being selectively adsorbed on the surface active nitrogen sites ${ }^{15,16}$ and the multiple pore wall interactions with $\mathrm{CO}_{2}$ molecules. ${ }^{6,13}$ At high $\mathrm{CO}_{2}$ loading, as the active nitrogen sites and microporous surface became gradually saturated, the availability of sorption sites progressively decreased, leading to a lowering in the adsorption heat. ${ }^{16,24}$ We note that the $Q_{\mathrm{st}}$ of WNPC-3 decreases mildly with the increasing $\mathrm{CO}_{2}$ loading until a near-plateau is achieved, which suggests that the binding energies of $\mathrm{CO}_{2}$ in the pores are heterogeneous. ${ }^{30,31}$ However, the $Q_{\text {st }}$ value for WNPC-3 is comparable to that for un-doped carbon, ${ }^{38}$ which is much below the energy of covalent bonds and consistent with the fully reversible $\mathrm{CO}_{2}$ isotherm, suggesting that the $\mathrm{CO}_{2}$ release can be achieved by a pressure drop without heating. . $^{13,30,31}$

From the viewpoint of practical applications, the recyclability of an adsorbent is important, and thus, the multicycle adsorptions of $\mathrm{CO}_{2}$ on WNPC-3 were conducted at $25^{\circ} \mathrm{C}$. As can be seen in Fig. 6e, the $\mathrm{CO}_{2}$ uptake remains almost unchanged in four cycles, indicating that WNPC-3 has excellent recyclability and stability. It is worth noting that, after each adsorption cycle, the saturated WNPC-3 released $\mathrm{CO}_{2}$ by a pressure drop without heating, which should be attributed to its appropriate $Q_{\mathrm{st}}$ values.

\section{Conclusions}

In summary, $\mathrm{N}$-doped hierarchical porous carbon has been successfully synthesized in this work using renewable waste wool as the raw material. The resulting optimal sample WNPC-3 was endowed with a high specific surface area of $1351 \mathrm{~m}^{2} \mathrm{~g}^{-1}$, 
a hierarchical porous structure with a total pore volume of $0.78 \mathrm{~m}^{3} \mathrm{~g}^{-1}$, a micropore volume up to $0.54 \mathrm{~m}^{3} \mathrm{~g}^{-1}$ and a fine micropore volume as high as $0.30 \mathrm{~m}^{3} \mathrm{~g}^{-1}$, and a certain number of nitrogen and oxygen functional groups. The conspicuous synergetic effect of the textural characteristics and functional groups provides an excellent guarantee for $\mathrm{CO}_{2}$ capture performance. We demonstrate that micropores are principally responsible for $\mathrm{CO}_{2}$ capture at low pressure $(1 \mathrm{bar})$. Remarkably, WNPC-3 exhibits a good $\mathrm{CO}_{2}$ adsorption capability of $3.72 \mathrm{mmol} \mathrm{g}^{-1}$ under $0{ }^{\circ} \mathrm{C}$ at atmospheric pressure ( 1 bar). Furthermore, an appropriate $Q_{\text {st }}$ leads to WNPC-3 possessing an excellent $\mathrm{CO}_{2} / \mathrm{N}_{2}$ selectivity and a significant regenerability. More significantly, here the strategy we used provides an excellent method to make best use of the low-cost yet abundant resources endowed by nature to fabricate sustainable carbon adsorbents for selective $\mathrm{CO}_{2}$ capture, thus opening new ways to set up an economical platform for practical applications.

\section{Conflicts of interest}

There are no conflicts to declare.

\section{Acknowledgements}

This work was supported by the Henan Province Colleges and Universities Key Research Project (18A620002, 18A150005), China Postdoctoral Science Foundation (2018M632775), the Henan Polytechnic University Doctor Foundation (660107/017), the Academician Workstation Innovation Foundation (13160093/010), the Program for Innovative Research Team in University of Ministry of Education of China (IRT_16R22) and the NSFC (No. U1704146).

\section{Notes and references}

1 R. S. Haszeldine, Science, 2009, 325, 1647-1652.

2 J. D. Figueroa, T. Fout, S. Plasynski, H. McIlvried and

R. D. Srivastava, Int. J. Greenhouse Gas Control, 2008, 2, 9-20.

3 D. M. D'Alessandro, B. Smit and J. R. Long, Angew. Chem., Int. Ed., 2010, 49, 6058-6082.

4 X. Ma, X. Wang and C. Song, J. Am. Chem. Soc., 2009, 131, 5777-5783.

5 G. T. Rochelle, Science, 2009, 325, 1652-1654.

6 J. Kou and L. B. Sun, Ind. Eng. Chem. Res., 2016, 55, 1091610925.

7 S. Gadipelli, H. A. Patel and Z. Guo, Adv. Mater., 2015, 27, 4903-4909.

8 S. Gadipelli, Y. Lu, N. T. Skipper, T. Yildirim and Z. Guo, J. Mater. Chem. A, 2017, 5, 17833-17840.

9 M. Niu, H. Yang, X. Zhang, Y. Wang and A. Tang, ACS Appl. Mater. Interfaces, 2016, 8, 17312-17320.

$10 \mathrm{~J} . \mathrm{Yu}$, L. H. Xie, J. R. Li, Y. Ma, J. M. Seminario and P. B. Balbuena, Chem. Rev., 2017, 117, 9674-9754.

11 S. Gadipelli, W. Travis, W. Zhou and Z. Guo, Energy Environ. Sci., 2014, 7, 2232-2238.

12 S. Gadipelli and Z. Guo, Chem. Mater., 2014, 26, 6333-6338.
13 T. Islamoglu, S. Behera, Z. Kahveci, T. D. Tessema, P. Jena and H. M. El-Kaderi, ACS Appl. Mater. Interfaces, 2016, 8, 14648-14655.

14 T. H. Nguyen, S. Kim, M. Yoon and T. H. Bae, ChemSusChem, 2016, 9, 455-461.

15 N. Fu, H. M. Wei, H. L. Lin, L. Li, C. H. Ji, N. B. Yu, H. J. Chen, S. Han and G. Y. Xiao, ACS Appl. Mater. Interfaces, 2017, 9, 9955-9963.

16 M. Yang, L. Guo, G. Hu, X. Hu, J. Chen, S. Shen, W. Dai and M. Fan, Ind. Eng. Chem. Res., 2016, 55, 757-765.

17 A. S. Jalilov, G. Ruan, C. C. Hwang, D. E. Schipper, J. J. Tour, Y. Li, H. Fei, E. L. G. Samuel and J. M. Tour, ACS Appl. Mater. Interfaces, 2015, 7, 1376-1382.

18 J. Zhang, X. Wang, G. Qi, B. Li, Z. Song, H. Jiang, X. Zhang and J. Qiao, Carbon, 2016, 96, 864-870.

19 H. Wei, W. Qian, N. Fu, H. Chen, J. Liu, X. Jiang, G. Lan, H. Lin and S. Han, J. Mater. Sci., 2017, 52, 10308-10320.

20 N. P. Wickramaratne and M. Jaroniec, ACS Appl. Mater. Interfaces, 2013, 5, 1849-1855.

21 M. Sevilla and A. B. Fuertes, Energy Environ. Sci., 2011, 4, 1765-1771.

22 J. W. F. To, J. He, J. Mei, R. Haghpanah, Z. Chen, T. Kurosawa, S. Chen, W. G. Bae, L. Pan, J. B. H. Tok, J. Wilcox and Z. Bao, J. Am. Chem. Soc., 2016, 138, 1001-1009.

23 G. Sethia and A. Sayari, Carbon, 2015, 93, 68-80.

24 L. Liu, Z. H. Xie, Q. F. Deng, X. X. Hou and Z. Y. Yuan, J. Mater. Chem. A, 2017, 5, 418-425.

25 X. Fan, L. Zhang, G. Zhang, Z. Shu and J. Shi, Carbon, 2013, 61, 423-430.

26 Y. Li, B. Zou, C. Hu and M. Cao, Carbon, 2016, 99, 79-89.

27 M. Sevilla, P. Valle-Vigon and A. B. Fuertes, Adv. Funct. Mater., 2011, 21, 2781-2787.

28 D. Lee, C. Z. Zhang, C. Wei, B. L. Ashfeld and H. Gao, J. Mater. Chem., 2013, 1, 14862-14867.

29 P. Wang, Y. Guo, C. Zhao, J. Yan and P. Lu, Appl. Energy, 2017, 201, 34-44.

30 J. Chen, J. Yang, G. Hu, X. Hu, Z. Li, S. Shen, M. Radosz and M. Fan, ACS Sustainable Chem. Eng., 2016, 4, 1439-1445.

31 M. Yang, L. Guo, G. Hu, X. Hu, L. Xu, J. Chen, W. Dai and M. Fan, Environ. Sci. Technol., 2015, 49, 7063-7070.

32 T. Liang, C. Chen, X. Li and J. Zhang, Langmuir, 2016, 32, 8042-8049.

33 B. Zhu, C. Shang and Z. Guo, ACS Sustainable Chem. Eng., 2016, 4, 1050-1057.

34 A. Alabadi, S. Razzaque, Y. Yang, S. Chen and B. Tan, Chem. Eng. J., 2015, 281, 606-612.

35 S. Gadipelli and Z. X. Guo, Prog. Mater. Sci., 2015, 69, 1-60. 36 S. Gadipelli, J. Burressa and T. Yildirim, Energy Environ. Sci., 2012, 5, 6453-6459.

37 K. V. Kumar, S. Gadipelli, K. Preuss, H. Porwal, T. Zhao, Z. X. Guo and M. M. Titirici, ChemSusChem, 2017, 10, 199209.

38 W. Travis, S. Gadipelli and Z. Guo, RSC Adv., 2015, 5, 2955829562.

39 G. Cui, Y. Dong, B. Li, Y. Li and P. Wang, Fibers Polym., 2017, 18, 713-719. 
40 G. Cui, Y. Dong, Y. Li, W. Shen and Z. Chen, Color. Technol., 2017, 133, 200-208.

41 L. Zhou, H. Cao, S. Zhu, L. Hou and C. Yuan, Green Chem., 2015, 17, 2373-2382.

42 H. Wei, H. Chen, N. Fu, J. Chen, G. Lan, W. Qian, Y. Liu, H. Lin and S. Han, Electrochim. Acta, 2017, 231, 403-411.

43 D. Liu, W. Zhang, H. Lin, Y. Li, H. Lu and Y. Wang, RSC Adv., 2015, 5, 19294-19300.

44 T. Wei, X. Wei, Y. Gao and H. Li, Electrochim. Acta, 2015, 169, 186-194.

45 Y. Li and M. Cao, Chem.-Asian J., 2015, 10, 1496-1504.

46 J. Wang, R. Krishna, X. Wu, Y. Sun and S. Deng, Langmuir, 2015, 31, 9845-9852.

47 J. Wang, R. Krishna, J. Yang and S. Deng, Environ. Sci. Technol., 2015, 49, 9364-9373.

48 Y. Sudaryanto, S. B. Hartono, W. Irawaty, H. Hindarso and S. Ismadji, Bioresour. Technol., 2006, 97, 734-739.

49 R. Q. Sun, L. B. Sun, Y. Chun and Q. H. Xu, Carbon, 2008, 46, 1757-1764.

50 S. J. Park and W. Y. Jung, J. Colloid Interface Sci., 2002, 250, 93-98.

51 J. L. Figueiredo, M. F. R. Pereira, M. M. A. Freitas and J. J. M. Órfão, Carbon, 1999, 37, 1379-1389.

52 J. Cai, J. Qi, C. Yang and X. Zhao, ACS Appl. Mater. Interfaces, 2014, 6, 3703-3711.

53 J. Ludwinowicz and M. Jaroniec, Carbon, 2015, 82, 297-303. 54 C. Zhang, W. Song, Q. Ma, L. Xie, X. Zhang and H. Guo, Energy Fuels, 2016, 30, 4181-4190.

55 M. A. Lillo-Ródenas, D. Cazorla-Amorós and A. LinaresSolano, Carbon, 2003, 41, 267-275.
56 P. Cheng, T. Li, H. Yu, L. Zhi, Z. Liu and Z. Lei, J. Phys. Chem. C, 2016, 120, 2079-2086.

57 N. P. Wickramaratne and M. Jaroniec, Adsorption, 2014, 20, 287-293.

58 N. P. Wickramaratne, J. Xu, M. Wang, L. Zhu, L. Dai and M. Jaroniec, Chem. Mater., 2014, 26, 2820-2828.

59 S. Gadipelli, V. Krungleviciute, Z. X. Guo and T. Yildirim, Energy Environ. Sci., 2014, 7, 335-342.

60 Z. Zhang, J. Zhou, W. Xing, Q. Xue, Z. Yan, S. Zhuo and S. Z. Qiao, Phys. Chem. Chem. Phys., 2013, 15, 2523-2529.

61 V. Presser, J. McDonough, S. H. Yeon and Y. Gogotsi, Energy Environ. Sci., 2011, 4, 3059-3066.

62 J. Wang, I. Senkovska, M. Oschatz, M. R. Lohe, L. Borchardt, A. Heerwig, Q. Liu and S. Kaskel, ACS Appl. Mater. Interfaces, 2013, 5, 3160-3167.

63 S. M. Mahurin, J. Gorka, K. M. Nelson, R. T. Mayes and S. Dai, Carbon, 2014, 67, 457-464.

64 R. Narasimman, S. Vijayan and K. Prabhakaran, RSC Adv., 2014, 4, 578-582.

65 T. Islamoglu, M. G. Rabbani and H. M. El-Kaderi, J. Mater. Chem. A, 2013, 1, 10259-10266.

66 S. Bandyopadhyay, A. G. Anil, A. James and A. Patra, ACS Appl. Mater. Interfaces, 2016, 8, 27669-27678.

67 Y. Shi, J. Zhu, X. Liu, G. Geng and L. Sun, ACS Appl. Mater. Interfaces, 2014, 6, 20340-20349.

68 S. Gadipelli and Z. X. Guo, ChemSusChem, 2015, 8, 21232132.

69 R. Li, X. Ren, X. Feng, X. Li, C. Hu and B. Wang, Chem. Commun., 2014, 50, 6894-6897.

70 M. Dinca and J. R. Long, J. Am. Chem. Soc., 2005, 127, 93769377. 